\title{
Cardiac Rehabilitation in Patients after Acute Myocardial Infarction
}

\section{Leonardo S. Roever-Borges ${ }^{1 *}$, Bastos EMRD ${ }^{2}$ and Resende ES ${ }^{1}$}

${ }^{1}$ Department of Clinical Research, Federal University of Uberlândia, Brazil

${ }^{2}$ Department of Physical Rehabilitation, Clinical Hospital, Federal University of Uberlândia, Brazil

*Corresponding author: Leonardo S. Roever-Borges, Av. Para, 1720 - Bairro Umuarama, Uberlândia - MG - CEP 38400-902, Brazil, Tel: +553488039878; E-mail: leonardoroever@hotmail.com

Received date: August 26, 2015; Accepted date: August 31, 2015; Published date: September 2, 2015

Copyright: ( 2015 Roever L. This is an open-access article distributed under the terms of the Creative Commons Attribution License, which permits unrestricted use, distribution, and reproduction in any medium, provided the original author and source are credited.

\section{Editorial}

Cardiac rehabilitation (CR) for patients after acute myocardial infarction (AMI) is recommended by practice guidelines, and includes multifaceted interventions to improve atherosclerotic risk markers, lifestyle, exercise capacity, quality of life, increases life expectancy, suppresses hospitalization frequency in patients with cardiovascular disease and has been shown to be cost-effective. CR programs include individualized exercise regimens, structured support focused on cardiovascular risk reduction, health education, nutrition counseling, psychosocial and vocational support, and medication adherence [1-3].

The exercise test provides for the appropriate training intensity prescription by heart rate reserve $\left(40 \%-80 \%\right.$ of peak), $\mathrm{O}_{2}$ reserve ( $40 \%-80 \%$ of peak), percent of peak exercise heart rate achieved $(65 \%-$ $80 \%$ ), and rating perceived exertion (11-16 on a 6-to-20 Borg scale), the exercises are performed below the ischemic threshold [4-6]. The CR should include endurance activities, balance, coordination, flexibility and stretching. Patients typically attend 2 to 5 sessions weekly for 30 to 60 minutes with up to 36 to 40 sessions. The components of each session should contain heating and cooling periods with duration of 5 to 10 minutes each, with field or walking on the treadmill. Strengthening exercises may be performed 2 to 3 times per week with 6 to 15 repeats per muscle group at intervals of 30 seconds to one minute, with intensity $40-70 \%$ of maximal voluntary contraction, reaching 5 series 10 repetitions with $70-80 \%$ of maximum voluntary contraction. Exercise prescription should be individualized according to clinical condition of the patient taking into account the individual limitations or comorbidities (orthopedic, neurological, respiratory, nephrology, infectious, among others) [4-7]. Adherence methods of the CR program should be implemented in this population towards a lower morbidity and mortality as well as a reduction in spending on hospitalizations.

\section{References}

1. Doll JA, Hellkamp A, Ho PM, Kontos MC, Whooley MA, et al. (2015) Participation in Cardiac Rehabilitation Programs Among Older Patients After Acute Myocardial Infarction. JAMA Intern Med.

2. Lavie CJ, Milani RV, Blumenthal JA (2014) Exercise, cardiac rehabilitation, and post-acute coronary syndrome depression. JAMA Intern Med 174: 165-166.

3. Fletcher GF, Ades PA, Kligfield P, Arena R, Balady GJ, et al. (2013) Exercise standards for testing and training: a scientific statement from the American Heart Association. Circulation 128: 873-934.

4. American College of Sports Medicine (2013). ACSM's Guidelines for Exercise Testing and Prescription. 9th ed. Baltimore, MD: Lippincott Williams \& Wilkins.

5. Herdy AH, López-Jiménez F, Terzic CP, Milani M, Stein R, et al. (2014) South American guidelines for cardiovascular disease prevention and rehabilitation. Arq Bras Cardiol 103: 1-31.

6. AACVPR (2004) Guidelines for Cardiac Rehabilitation and Secondary Prevention Programs. 4th ed. Champaign, IL: Human Kinetics Publishers, Inc.

7. Kobashigawa JA, Leaf DA, Lee N, Gleeson MP, Liu H, et al. (1999) A controlled trial of exercise rehabilitation after heart transplantation. N Engl J Med 340: 272-277. 